\title{
Preparation of poly(D-L-lactide) nanoparticles assisted by amphiphilic poly(methyl methacrylate-co-methacrylic acid) copolymers
}

\author{
Gautier $\mathrm{S}^{[1]}$, Grudzielski $\mathrm{N}^{[2]}$, Goffinet $\mathrm{G}^{[2]}$, Henry de Hassonville $\mathrm{S}^{[3]}$, Delattre $\mathrm{L}^{[3]}$ Jérôme $\mathrm{R}^{[1]}$ \\ ${ }^{[1]}$ Center for Education and Research on Macromolecules, University of Liège, B-4000 Liège, Belgium \\ ${ }^{[2]}$ Biology and Structural Morphology Laboratory, University of Liege, B-4000 Liège, Belgium \\ ${ }^{[3]}$ Pharmaceutical Technology Laborator, University of Liège, B-4000 Liège, Belgium
}

\begin{abstract}
When co-precipitated with amphiphilic copolymers from DMSO, poly(D,L-lactide) (PLA) can be readily converted into stable sub-200 nm nanoparticles by addition of an aqueous phase, free of any polymeric stabilizers such as poly(vinyl alcohol) or Poloxamer In this work, the ability of random poly(methyl methaciylate-co-methacrylic acid) copolymers (PMMA-co-MA) to stabilize PLA nanoparticles was demonstrated, and the properties of PLA/PMMA-co-MA nanoparticles were investigated When co-precipitated with PMMA-co-MA, PLA was totally converted into nanoparticles using a polymer concentration in DMSO $(\mathrm{Cp})$ below $17.6 \mathrm{mgml}^{-1}$, and a PMMA-co-MA proportion above a critical value depending on the content of MA repeating units $(X)$ For instance, the lowest PMMA-co-MA proportion required was $09 \mathrm{mgmg}^{-1}$ PLA for $X=12 \%$, and $0.5 \mathrm{mgmg}^{-1}$ PLA for $X=$ $25 \%$ (for $\mathrm{C}_{\mathrm{PLA}}=16 \mathrm{mgml}^{-1} \mathrm{DMSO}$ ). The nanoparticle diameter was essentially independent of $X$, the proportion of PMMA-co-MA, and the PLA molecular weight, except for oligomers for which the nanoparticle diameter was smaller. It decreased when the organic phase was diluted $(126 \pm 13 \mathrm{nmfor}$ $\mathrm{Cp}=17.6 \mathrm{mgml}^{-1}$, and $\left.81 \pm 5 \mathrm{nmfor} \mathrm{Cp}=5.6 \mathrm{mgml}^{-1}\right)$. The time-dependence of the stability and the degradation of PLA/PMMA-co-MA nanoparticles was discussed. One of the main advantages of this technique is the ability to control surface properties and to bring functional groups to otherwise nonfunctionalized PLA nanoparticles To illustrate this, a conjugate of PMMA-co-MA25 and biotin was synthesized, and used to prepare biotinylated nanoparticles that could be detected by fluorescence and transmission election microscopy after infiltration into ligatured rat small intestine.
\end{abstract}

Key words: Nanoparticles; polylactide; controlled radical polymerization; amphiphilic copolymers; drug carrier; oral administration; biotin conjugate.

\section{Introduction}

This work is part of a general strategy aimed at designing a simple and efficient nanoprecipitation technique for the encapsulation of high molecular weight therapeutic agents, such as peptides and proteins, in bioresorbable nanoparticles, preferably with a diameter smaller than $200 \mathrm{~nm}$. The use of solvents as benign as possible, together with high entrapment yields, acceptable retention of biological activity and minimized migration towards the particle surface are among the requirements to be fulfilled.

Several techniques have been published for the preparation of nanoparticles from aliphatic polyesters based on lactide, glycolide, and $\varepsilon$-caprolactone [1, 2], As a rule, they rely on polymer precipitation from an organic solution into an aqueous phase in the presence of a water-soluble stabilizing agent, such as polyvinyl alcohol) (PVA), or PPO-PEO-PPO triblock copolymers known as Poloxamers. In the emulsion-evaporation technique, commonly used to prepare microspheres, the non water-miscible organic phase is emulsified with a high mechanical energy, prior to polymer precipitation by addition of a large volume of water containing the stabilizing agent [3-6], In the emulsion-diffusion technique, the organic solvent is partially water-miscible (eg. ethylacetate, benzyl alcohol) and saturated with water. The emulsification then requires less mechanical energy, and smaller particles are usually formed $[7,8]$. Nevertheless, the nanoparticle diameter remains rather large $(>2.50 \mathrm{~nm})$ and substantial amounts of stabilizing agents are usually used (e.g. PVA/polylactide weight ratio of 1 for emulsiondiffusion in ethylacetate [9])., Nanoprecipitation (or solvent displacement) and salting-out are alternative techniques based on the direct precipitation of the polymer dissolved in a water-miscible 
solvent (e.g. acetone, acetonitrile, ethanol) by addition of the aqueous phase [10-14]. Nanoprecipitation was initially reported for the preparation of nanocapsules with an oily core [15]. In the 'salting-out' technique, polymer precipitation is triggered by addition of the aqueous phase containing either an electrolyte or a sugar, together with a stabilizing agent, such that the polymer phase separation is fast and favors higher yields in particles and encapsulation [16], Both nanoprecipitation techniques lead to smaller particle size than emulsion-evaporation does, but again, they seem to require the use of polymeric water-soluble stabilizers such as PVA or Poloxamer. Purification techniques like cross-flow filtration are used to eliminate the stabilizer, together with residual solvent and non-encapsulated drug. Whatever the purification technique, the stabilizer can remain associated with the nanoparticles to an extent which is difficult to control. Interestingly, it has been suggested that a minimum amount of residual stabilizer is actually necessary to the stabilization of the nanopartides [17].

According to our initial technique, small amounts of an amphiphilic copolymer like Poloxamer are dissolved together with poly(D,L-lactide) (PLA) in the organic phase rather that in the aqueous one, so that the copolymer remains permanently associated with PLA within nanoparticles after precipitation [18]. The role of the hydrophobic units is to anchor the copolymer to the PLA matrix, whereas hydrophilic units localized at the particle surface are expected to form a coalescence barrier. Properly designed amphiphilic copolymers are, therefore, expected to control the size and surface properties of the nanoparticles. These two features are known to influence the in vivo biodistribution of such carriers, either across epithelial barriers, or after transfer into the blood compartment $[1,19]$, This paper reports on the use of amphiphilic random copolymers of methylmethacrylate and methacrylic acid (PMMA-coMA) for the stabilization of poly(D,L-lactide) nanoparticles. Advantage of the progress in macromolecular engineering was taken to synthesize copolymers of well-defined composition and architecture. Dimethylsulfoxide was used as the water-miscible solvent, as it is a good solvent for polypeptides and most aliphatic polyesters (except for homopolymers of glycolide and $\varepsilon$-caprolactone) and is known for having a low systemic toxicity [20]. The study was divided in three parts. In the first one, the conditions for optimal precipitation of PLA were sought, Several addition modes of the organic and aqueous phases were compared. The minimum proportion of PMMA-co-MA to obtain stable nanoparticles with a $100 \%$ yield was determined. The size distribution of the nanoparticles was shown to depend on the polymer concentration in the organic phase and on the PLA molecular weight, In the second, the stability of PLA/PMMA-co-MA suspensions under different storage conditions was investigated The third one deals with a strategy to label the nanoparticles with biotin for histologic observations, which was applied to trace nanoparticles after intestinal infiltration in rat.

\section{Materials and methods}

Synthesis of amphiphilic PMMA-co-MAx copolymers

Methyl methacrylate-co-methacrylic acid random copolymers (PMMA-co-MA $)$, where $X$ is the molar fraction of MA units, were synthesized in two steps, starting by atom transfer radical polymerization of methyl methacrylate and trimethylsilyl methacrylate, followed by cleavage of the silylated group. Briefly, for PMMA-co-MA10 with an expected degree of polymerization of 140, 0.149 $\mathrm{g}$ of dibromobis(triphenylphosphine) nickel bromide (Aldrich, $2 \times 10^{-4} \mathrm{~mol}$ ), .5,4 ml of methyl methacrylate MMA (Aldrich, $5.1 \times 10^{-2} \mathrm{~mol}$ ) and $1 \mathrm{ml}$ of trimethylsilyl methacrylate (MAP, Aldrich, $5.6 \times 10^{-4} \mathrm{~mol}$ ) were mixed under nitrogen. Four ml of a $0.1 \mathrm{~mol} \mathrm{1}^{-1}$ solution of 2-bromo-ethylisobutyrate (Aldrich, 4 x $10^{-4}$ $\mathrm{mol}$ ) in toluene were added, and the mixture was placed at $80{ }^{\circ} \mathrm{C}$ overnight $[21,22]$. In the second step, treatment of the polymer in methanol resulted in the quantitative deprotection of acid groups. The catalyst was further removed by elution on alumin. The number average molecular weight and polymolecularity of protected PMMA-co-MAP copolymers were determined by size exclusion chromatography (SEC) in THF, with respect to PMMA standards (Table 1), The molar fraction of MAP units was determined by ${ }^{1} \mathrm{H}-\mathrm{NMR}$ in $\mathrm{CDCI}_{3}$, and estimated to be equal to the molar fraction of MA units $(X)$ (Table 1). 
Table 1. Molecular characteristics of PMMA-co-MA-copolymers, minimum proportion of PMMA-co$M A_{x}$, and minimum molar proportion of MA units compared with PL A required for a total conversion $P L A$ into stable nanoparticles, starting from $C_{P L A}=16 \mathrm{mgml}^{-1}$ in DMSO

\begin{tabular}{lllll}
$X$ & $\mathrm{M}_{\mathrm{n}}\left(\mathrm{x}^{3}\right)$ & $\mathrm{M}_{\mathrm{w}} / \mathrm{M}_{\mathrm{n}}$ & $\begin{array}{l}\text { PMMA-co-MA } \\
(\mathrm{w} / \mathrm{w})\end{array}$ & $\begin{array}{l}\mathrm{MA} \\
\left(10^{-6} \mathrm{molmg}^{-1} \text { PLA }\right)\end{array}$ \\
\hline 5 & 17 & 1.2 & $\overline{\boldsymbol{a}}$ & $\boldsymbol{a}$ \\
10 & 11 & 1.4 & $15: 100$ & 11 \\
12 & 24 & 1.2 & $9: 100$ & 13 \\
25 & 13 & 1.1 & $5: 100$ &
\end{tabular}

${ }^{a}$ For $\mathrm{X}=5 \%$, conversion into nanoparticles is only partial whatever the proportion of PMMA-co-MA ${ }_{\mathrm{X}}$.

Nanoprecipitation of poly(D,L-lactide) with PMMA-co-MAx

Poly(D,L-lactide) (R-206, PLA) was supplied by Boehringer (Germany), with $\mathrm{M}_{\mathrm{n}}=477.50$ and $M_{w} / M_{n}=1.77$, as determined by SEC in THF with universal calibration.. In a typical experiment, PLA (16 mg) and PMMA-co-MA- (1,6 mg) were dissolved in $1 \mathrm{ml}$ DMSO (Acros). Six ml of phosphate buffer $(0.13 \mathrm{M}, \mathrm{pH} 7.4)$ were rapidly added to the polymer solution with no additional stirring. The suspension was dialyzed against water or saline solution $(\mathrm{NaCl} 0.9 \%)$ in order to remove DMSO (Spectra/Por-1 membrane, molecular weight cut-off of 6000-8000, Spectrum). The final volume was adjusted to $8 \mathrm{ml}$, so as to reach a PLA concentration (CPLA) of $2 \mathrm{mgml}^{-1}$, The suspension was then slightly centrifuged (10 min at $3500 \mathrm{rpm})$ in order to eliminate any insoluble component, including precipitates or dusts, prior to analysis by dynamic light scattering (DLS), transmission electron microscopy (TEM), and turbidimetry measurements by UV-visible spectrometry, Three additional modes of the organic phase (solution of $16 \mathrm{mg}$ PLA and $1.6 \mathrm{mg}$ PMMA-co-MA 12 in $1 \mathrm{ml} \mathrm{DMSO}$ ) and aqueous phase were compared, which differ in the order of addition, addition rate (dropwise or at once), and stirring (with or without). Mode A consisted of the rapid addition of the aqueous phase to the organic one, without stirring, as described above. For mode B, the organic phase was added dropwise into the aqueous phase under gentle magnetic stirring. For mode $\mathrm{C}$, the aqueous phase was added dropwise into the organic phase under gentle magnetic stirring. Each experiment was performed three times independently.

\section{Characterization of nanoparticle suspensions}

Dynamic light scattering (DLS) was carried out with a Brookhaven instrument (Ar laser, $488 \mathrm{~nm}$ ), after dilution of the suspensions by filtered deionized water to yield a PLA concentration of about $200 \mu \mathrm{g}$ $\mathrm{ml}^{-1}$. The size distribution was calculated by the Contin method, and data from at least five measurements was averaged for each sample. Transmission electron microscopy (TEM) observations were performed using a Philips CM-100 microscope.

Table 2. Mean diameter of PLA/PMMA-co-MA12 (100:10) nanopatticles after resuspension in different volumes of phosphate buffer (0 $13 \mathrm{M}$, pH 7.4)

\begin{tabular}{llll}
\hline$V_{i} / V^{a}$ & $\mathrm{C}_{\mathrm{PLA}}{ }^{\mathrm{b}}\left(\mathrm{mgml}^{-1}\right)$ & Mean diameter $(\mathrm{nm})$ & Observations \\
\hline 1 & 0.8 & $136 \pm 12$ & slightly turbid \\
2 & 1.6 & $135 \pm 16$ & turbid, few precipitates \\
5 & 4 & $141 \pm 21$ & turbid, few precipitates \\
10 & 8 & $139 \pm 10$ & very turbid, precipitates \\
25 & 20 & $154 \pm 13$ & very turbid, precipitates
\end{tabular}

${ }^{a}$ Ratio of initial volume (DMSO) to final aqueous volume (DMSO/phosphate buffet mixture) ${ }^{b}$ Theoretical concentration of PLA nanoparticles in suspension

The samples were prepared by freeze-drying of a drop of diluted suspension on copper grids coated with Formvar. The zeta potential of nanoparticles suspended in unbuffered saline solution $(\mathrm{NaCl} 0.9 \%)$ was measured by Doppler electrophoretic light scattering (Coulter Delsa 440-SX) at angles 25.6 and 3.5.2 deg. Turbidimetry measurements were carried out by UV-visible spectrometry (Hitachi 3300). 


\section{Precipitation at acidic $\mathrm{pH}$ and resuspension in phosphate buffer}

Aliquots of a $0.8 \mathrm{mgml}^{-1}$ suspension of PLA/PMMA-co-MA 12 nanoparticles $(100: 10, \mathrm{w} / \mathrm{w})$ were acidified by $100 \mu l$ of glacial acetic acid down to $\mathrm{pH} 4$. They were centrifuged (10 min at $3.500 \mathrm{rpm}$ ), and the acidic supernatant was replaced by variable volumes of phosphate buffer (0.13 $\mathrm{M}, \mathrm{pH} 7.4)$, such that CPLA ranged between 1.6 and $20 \mathrm{mgml}^{-1}$ (Table 2). The suspensions were vortexed and stored at $4^{\circ} \mathrm{C}$ for 5 days. Precipitates were eliminated by gentle centrifugation ( $5 \mathrm{~min}$ at $2500 \mathrm{rpm}$ ) prior to DLS analysis.

\section{Degradability and stability studies}

In a first study, a suspension of PLA/PMMA-co-MA12 nanoparticles (100:10) in pure water (2 $\mathrm{mgml}^{-}$ 1 ) was separated into several aliquots, and stored at $37^{\circ} \mathrm{C}$. Two aliquots were withdrawn at regular intervals for 46 days. Each aliquot was divided in two fractions, one for DLS analysis, and the second for SEC in THF after lyophilization. The $\mathrm{pH}$ of all aliquots was systematically measured. In a second study, two suspensions of PLA/PMMA-co-MA 12 nanoparticles (100:10) in $0.13 \mathrm{M}$ phosphate buffer $\left(2 \mathrm{mgml}^{-1}\right)$ at $\mathrm{pH} 6$ and $\mathrm{pH} 7.4$ were stored at $4^{\circ} \mathrm{C}$. Aliquots were withdrawn at regular intervals for 15 days, and centrifuged at $3500 \mathrm{rpm}$ for $1.5 \mathrm{~min}$ prior to turbidity measurement by UV-visible spectrometry. The optical density was measured at 600,700 , and $8.50 \mathrm{~nm}$.

\section{PMMA-co-MA25-biotin conjugate}

$193 \mathrm{mg}$ of PMMA-co-MA25 were dissolved in $10 \mathrm{ml}$ DMF (Acros) at $0^{\circ} \mathrm{C} .11 . .3 \mathrm{mg}$ of dicyclohexylcarbodiimide (Sigma) in DMF, followed by $6.9 \mathrm{mg}$ of N-hydroxysuccinimide (Sigma) in DMF, were added dropwise. $25 \mathrm{mg}$ of N-(5-aminopentyl) biotinamide (biotin-cadaverine, Molecular Probes) and $5,7 \mathrm{mg}$ of triethylamine (Acros) were added at room temperature. The reaction mixture was kept under stirring for $15 \mathrm{~h}$. It was then filtered in order to eliminate dicy-clohexylurea, and dialyzed against phosphate buffer $(0.13 \mathrm{M}, \mathrm{pH} 7.4)$ and against water prior to lyophilization. $150 \mathrm{mg}$ of the sodium salt of the conjugate were collected. They were dissolved in acetone and acidified by concentrated $\mathrm{HC} 1$, followed by precipitation by diethylether to yield the conjugate under the acidic form. This step should eliminate unreacted biotin-cadaverin. The theoretical biotin content was 10 mol $\%$ of the MA units, i.e. $2.5 \mathrm{~mol} \%$ of the comonomer units. Both ${ }^{1} \mathrm{H}-\mathrm{NMR}$ and FTIR spectra of the conjugate (not shown) confirmed the presence of biotin, but the substitution degree was too low for quantitative analysis. For the same reason, it was difficult to confirm that biotin molecules were all covalently associated with the copolymer.

\section{Intestinal infiltration of nanoparticles labeled with biotin}

Biotin-labeled PLA nanoparticles were prepared with the PMMA-co-MA25 - biotin conjugate, following the nanoprecipitation procedure previously described, with PMMA-co-MA25-biotin /PLA 100:10. Female Sprague-Dawley rats ( $200 \mathrm{~g})$ were anesthetized by injection of ketamine and xylazine. The regulations of the 'Fonds National pour la Recherche Scientique' for care and use of laboratory animals were respected. After abdominal incision, part of the small intestine (jejunum and ileum) was ligatured. Five $\mathrm{ml}$ of a suspension of biotin nanoparticles $\left(\mathrm{C}_{\mathrm{PLA}}=2,2 \mathrm{mgml}^{-1}\right)$ were infiltrated by 1$\mathrm{ml}$ injections in different parts of the ligatured intestine portion. The animals were sacrificed at different intervals by exposure to $\mathrm{CO}_{2}$. Tissues were prepared for fluorescence microscopy and transmission electron microscopy (TEM, Jeol 100 SX). For fluorescence microscopy, frozen semi-thin sections were revealed with NeutrAvidin-rhodamine Red-X conjuguate (Molecular Probes) and cellular nuclei were counter stained with Sytox (Molecular Probes). Single and dual wavelengths were used to visualize separately the red (rhodamine) and green (Sytox) fluorescence. For TEM observations, ultrathin sections embedded in Unicryl resin [23] were revealed by streptavidin coupled to gold nanoparticles $(10 \mathrm{~nm}$, Sigma) and contrasted with uranyl acetate.

\section{Results and discussion}

Most techniques used to prepare nanoparticles of aliphatic polyesters require the presence of watersoluble polymeric stabilizers [2], most commonly PVA and Poloxamer. These can be removed, at least 
partly, by membrane filtration (cutoff $100 \mathrm{kDa}$ ) [24, 2.5], centrifugation [5, 26, 27], ultracentrifugation $[6,28]$, or cross-flow filtration $[17,29]$. The amount of residual stabilizer is rarely determined, although it may play an important role in the in vivo fate of nanopaiticulates as it can modify their surface composition [30-32]. Various efforts made to eliminate the stabilizer are cited below, and alternative techniques designed to avoid their use are presented.

After purification by membrane ultrafiltration of poly(D,L-lactide) nanoparticles prepared by emulsionevaporation with PVA (PVA/PLA $=1.6) 52 \%$ of the initial PVA remained associated with the nanoparticles [24], After ultrafiltration of poly(lactide-co-glycolide) (PLGA) nanoparticles, also prepared by emulsion-evaporation with PVA/PLGA $=1.6,90 \%$ of the stabilizer was removed, the remaining PVA being more likely adsorbed onto the particle surface [25], Scholes et al. compared the surface adsorption of PVA, Poloxamer and Poloxamine onto nanoparticles of PLGA prepared by emulsion-evaporation [28]. For PVA, gel filtration and centrifugation resulted in the same surface coverage measured by SIMS and XPS. For Poloxamer and Poloxamine, gel filtration seemed to be less efficient than centrifugation, probably because micelles formed by such copolymers are eluted together with the nanoparticles. Quintanar-Guerrero et al. used cross-flow filtration to purify poly(D,L-lactide) nanoparticles prepared by emulsion-diffusion with PVA and Poloxamer (stabilizer/PLA = 5) [17]. PVA showed the strongest affinity for PLA, and residual PVA $(6 \%)$ was actually necessary to stabilize the nanoparticles. In contrast, Poloxamer did not interact strongly with PLA, and residual Poloxamer found after purification (1.4\%) was unable to prevent nanoparticles from precipitating.

Alternative techniques which avoid the use of such stabilizers were reported. Nanocapsules of poly(Llactide) blended with a block PCL-PEO-PCL terpolymer (60:40) were prepared by w/o/w emulsionevaporation in order to encapsulate BSA, using low molecular weight surfactants like Span and Tween [33], However, the particle diameter was rather large (>560 nm). Human albumin [4] and hydrophobized dextrans [27] were successfully substituted for PVA in emulsion-evaporation. PLA-bPEO block copolymers (PLA/PEO $=2 / 5$ and 3/4) were used not only as alternative stabilizers, but also as a means to introduce PEO segments at the surface of PLGA nanoparticles prepared by nanoprecipitation [30, 34], The amount of PLA-b-PEO in the aqueous phase was rather high (PLA-b$\mathrm{PEO} / \mathrm{PLGA}=0.7 .5)$, and the minimum amount required for stabilization was not mentioned. Meanwhile, other studies reported on the use of PLA-b-PEO as a constituent of the organic phase, either alone or blended with PLGA in an emulsion-evaporation process using a stabilizer which was not specified [5]. Recently, PLA-b-PEO copolymers were also blended with PLA in a salting-out process using PVA [29], Last, nanoprecipitation of PLA and PLGA in the absence of stabilizer in the aqueous phase has been described in a few articles. For instance, Maruyama et al. prepared cationic nanoparticles of $\mathrm{P}(\mathrm{D}, \mathrm{L}-\mathrm{LA})\left(\mathrm{M}_{\mathrm{W}}=10000\right)$ by using dextran-grafted poly(L-lysine) (PLL-g-Dex) [35], PLL-g-Dex was mixed with PLA in DMSO (PLL-g-Dex/PLA $=0.2$ to 1.5), and the two polymers were co-precipitated by slow addition of water, similarly to our technique. The higher the PLL-gDex/PLA ratio, the smaller the nanoparticle diameter, which ranged from $300 \mathrm{~nm}$ (without PLL-Dex) down to less than $100 \mathrm{~nm}$. Interestingly, nanoparticles could be obtained with no PLL-g-Dex (300 nm) as with non-grafted PLL (250-300 nm). The diameter was however larger, suggesting that PLL-g-Dex acts not only as an additive to PLA, but also as a stabilizer,. Govender $e$ t al. also showed that is was possible to prepare PLGA $\left(\mathrm{M}_{\mathrm{W}}=10000\right)$ nanoparticles by precipitation from acetonitrile, without any stabilizer [36], Both the nanoparticle yield (>80\%) and the nanoparticle diameter (around $200 \mathrm{~nm}$ ) were acceptable, but the stability of the suspensions was not discussed. Last, Jung et al. found that sulfobutyl-PVA grafted with PLGA arms (PVA/PLGA =0.11) could precipitate into nanoparticules by solvent displacement, even without Poloxamer in the aqueous phase [14]. In the case of such brush copolymers, the presence of sulfobutyl charged groups at the nanoparticle surface probably accounts for the nanoparticle stabilization.

After examination of the literature, it becomes clear that there is a need for a technique which avoids the use of aqueous polymeric surfactants, thereby eliminating the need for purification. However, stabilization of the nanoparticles is still required when dealing with high molecular weight PLA. We previously reported that stable poly(D,L-lactide) nanoparticles can be obtained by simple nanoprecipitation from DMSO, in the presence of low and high molecular weight stabilizers like cholesteryl sulfate or Poloxamer dissolved in the organic phase together with PLA [18]. In the present study, the use of amphiphilic PMMA-co-MA copolymers designed to ensure a durable stabilization of PLA nanoparticles was investigated. PMMA-co-MA were synthesized by controlled radical polymerization, so that their molecular characteristics — molecular weight, polymolecularity and composition — were well-defined (Table 1). 
It was first observed that poly(D,L-lactide) was readily converted into stable nanoparticles by coprecipitation with $10 \mathrm{mg}$ of PMMA-co-MA12 per $100 \mathrm{mg}$ of PLA both dissolved in DMSO, upon rapid addition of phosphate buffer $(0,1.3 \mathrm{M}, \mathrm{pH} 7.4)$. The conversion of PLA into nanoparticles was quantitative, as indicated by the negligible amount of precipitates collected after mild centrifugation of the suspension. The nanoparticles remained stable after removal of DMSO by dialysis against water or $\mathrm{NaCl} 0.9 \%$, as the result of electrostatic repulsion between caiboxylate groups. They also remained in suspension when centrifuged at low speed (3500 rpm), a higher speed like $14000 \mathrm{rpm}$ being necessary for total precipitation. When using a polymer concentration (CP) of $17.6 \mathrm{mgml}^{-1}$ in DMSO, the mean diameter of the nanoparticles ranged from 110 to $140 \mathrm{~nm}$, with a relatively high polydispersity. The zeta potential of PLA/PMMA-co-MA12 (100:10) nanoparticles in saline solution and pH between 70 and 7.2 was $-60 \mathrm{mV}$, thus confirming the presence of carboxylate groups at the nanoparticle surface. This can be beneficial in cases where transepithelial transport is desired, as increasing degrees of negatively charged groups were found to increase the affinity of nanoparticles to intestinal Caco-2 cells monolayers [14], Without copolymer, starting from the same $\mathrm{Cp}$ of $17.6 \mathrm{mgml}^{-1}$ of DMSO by addition of phosphate buffer, PLA did not precipitate into nanoparticles, but rather into large aggregates which eventually sedimentate.

In the literature dealing with nanoprecipitation, water-miscible solvents are said to form nanodroplets when poured into the aqueous phase, due to interfacial turbulence [2]. The polymer precipitates as the result of the diffusion of the organic phase into the aqueous phase, and the size of the nanoparticles is related to that of the original nanodroplets. The water-soluble polymeric stabilizer is thus necessary to impart enough stability to the nanoparticles once they are formed. What we found however is that PLA nanoparticles can be produced without any stabilizer in the aqueous phase and without any mechanical dispersion, merely by precipitation from DMSO together with a small amount of an amphiphilic PMMA-co-MA copolymer. Indeed, the hydrophilic carboxylic acid groups of the MA units — which turn into sodium carboxylate in contact with the aqueous phase buffered at $\mathrm{pH} 7.4$ - are expected to be driven towards the water phase during precipitation and to accumulate at the nanoparticle surface, thus creating an electrostatic barrier to coalescence. Meanwhile, the hydrophobic MMA units contribute to a durable anchorage of the copolymer into the PLA matrix. To our best knowledge, coprecipitation of PLA with a copolymer has been reported only once, by Maruyama et at. who used dextran-grafted poly(L-lysine) copolymers to obtain cationic PLA nanoparticles as already mentioned above [3.5]. In the study of Go vender et al. [36], PLGA alone was precipitated as nanoparticles smaller than $200 \mathrm{~nm}$ with acceptable yields, from acetonitrile. The zeta potential of the nanoparticles was $-49.2 \pm 0.7 \mathrm{mV}$ at $\mathrm{pH} 7.4$. This negative value reveals that PLGA carboxylic acid end groups are present at the nanoparticle surface, which is probably due to the low average molecular weight of the selected PLGA $\left(\mathrm{M}_{\mathrm{W}}=10000\right)$. The PLGA carboxylate end groups are probably sufficient to stabilize the nanoparticles. The PLA we used in our study has a higher molecular weight $\left(\mathrm{M}_{\mathrm{n}}=477.50\right)$ and could not be precipitated into nanoparticles as such, from either DMSO or acetonitrile. Influence of the addition mode on the size distribution of PLA/PMMA-co-MA nanoparticles. Using a constant proportion of PMMA-co-MA12 of $0.1 \mathrm{mgmg}^{-1}$ PLA, three addition modes of the organic and aqueous phases were compared at two polymer concentrations $(\mathrm{Cp})$ in DMSO. Both minimum and mean diameters were measured by DLS with the Contin calculation method (Table 3). The three addition modes led to quantitative nanoprecipitation of PLA. Whatever Cp, the A addition mode yielded the smallest nanoparticles, followed by the $\mathrm{C}$ mode. For instance, the mean diameter of the nanoparticles prepared at $\mathrm{Cp}=17.6 \mathrm{mgml}^{-1}$ was $121 \pm 14,158 \pm 1.5$, and $196 \pm 14 \mathrm{~nm}$, according to A, C, and B modes, respectively.

Polydispersity, as indicated by the variance calculated by the Contin method and the difference between the minimum and maximum diameters (not shown), was essentially independent of the addition mode.

The addition mode, i.e. the addition order and the stirring rate, is expected to influence the rate at which the viscosity of the polymer solution decreases when the water phase is added to the organic phase, prior to the onset of precipitation (dynamic viscosity of DMSO $=1.99 \mathrm{mPa} \mathrm{s}$, of water $=0.89$ $\mathrm{mPa} \mathrm{s}$ ), and thereby the size of the solvent nanodroplets into which the polymer is precipitating (as reviewed in reference [2]). It should also govern the rate at which the solvation of PLA decreases. Indeed, the nanoprecipitation process is controlled by thermodynamic interactions between the polymer and the solvent which can be approximated by solubility parameters. For instance, the Hildebrand parameter $(\delta)$ for DMSO is $24.6 \mathrm{MPa} 1 / 2$. For PLA in solvents with moderate H-bonding like DMSO, $\delta$ ranges between 17.4 and $30.1 \mathrm{MPa}^{1} / 2$ [37], The addition of water $\left(\delta=47.9 \mathrm{MPa}^{1} / 2\right)$ increases the $<5$ of DMSO, and a polymer/solvent phase separation occurs once the PLA solubility limit is reached. The 
particle size should then depend on the way the polymer phase grows beyond the solubility limit. For instance, larger particles are likely to be formed when the organic and aqueous phases are slowly mixed, because the polymer phase has more time to grow. Our results fit this rule, since the largest particles were obtained when the organic phase was added dropwise to the aqueous phase (B mode). Although addition mode $\mathrm{C}$ is based on the slow addition of the organic phase into a large aqueous volume, there is a very rapid decrease in the polymer solvency, accounting for the small particle diameter similar to that reported for the A mode. The $\delta$ for water/DMSO mixtures can be calculated from Eq. (1),

$$
\delta_{1+2}=v_{1} \cdot \delta_{1}+v_{2} \cdot \delta_{2},
$$

where $v_{1}$ and $v_{2}$ are the volume fractions of water and DMSO, $\delta_{1}=47.9 \mathrm{MPa}^{1 / 2}$ for water, and $\delta_{2}=$ 24.6 $\mathrm{MPa}^{1 / 2}$ for DMSO. On this basis, pure PLA should reach the solubility limit $\left(30.1 \mathrm{MPa}^{1 / 2}\right)$ for a water/DMSO ratio of ca. 0,4 , but it was found experimentally that a higher water/DMSO ratio (at least 1) was required to trigger cloudiness indicative of the onset of nanoprecipitation. This observation suggests that the presence of PMMA-co-MA increases the resistance of PLA to precipitation. Influence of the PMMA-co-MA hydrophilic/hydrophobic balance on the conversion into nanoparticles, Four PMMA-co-MAX copolymers with similar degree of polymerization $\left(M_{n}\right.$ from 11 to $\left.24 \times 10^{3}\right)$ and varying contents of MA units $(5-25 \mathrm{~mol} \%)$ were assessed for their ability to promote PLA nanoprecipitation according to addition mode A. The minimum amount of PMMA-co-MAX required to reach total conversion was determined, starting from a constant PLA concentration of $16 \mathrm{mgml}^{-1}$ in DMSO (Table 1). Partial conversion was characterized by the formation of larger unstable flakes. In the case of the less hydrophilic copolymer containing $5 \mathrm{~mol} \%$ of MA units, large unstable flakes of 20 $\mu \mathrm{m}$ diameter where formed whatever the copolymer proportion. Stable nanoparticles could be formed with all other copolymers. Although the minimum proportion of PMMA-co-MA was found to depend on the MA content, the minimum molar proportion of MA units was essentially in the same range for the three copolymer, from $9 \mu \mathrm{mol}$ to $1.5 \mu \mathrm{molmg}-1$ PLA This value actually corresponds to a critical coverage of the nanoparticles by charged MA units which provides a sufficient electrostatic barrier against coalescence, while the hydrophobic MMA units ensure anchorage within the PLA matrix. Influence of the polymer concentration in the organic phase $(\mathrm{Cp})$ on the size distribution of PLA/PMMA-co-MA 12 (100:10) nanoparticles. The mean diameter of PLA/PMMA-co-MAA 12 (100:10) nanoparticles was smaller when prepared from a polymer solution of C- $5.5 \mathrm{mg} \mathrm{ml}^{-1} \mathrm{DMSO}$ $(61 \pm .5 \mathrm{~nm})$ than when prepared from a 17,6 $\mathrm{mgml}^{-1}$ solution $(121 \pm 14 \mathrm{~nm})$ (Table 3$)$. A control of the diameter is of great interest, because the uptake of nanoparticles by epithelial barriers is known to depend on this feature [19]. Well calibrated nanoparticles are useful not only to understand the mechanisms of particle uptake for therapeutic applications, but also for toxicological studies related to the inhalation of atmospheric particulates.

On the other hand, three series of experiments were carried out in which $\mathrm{Cp}$ was changed from 19.3 to $0.6 \mathrm{mgml}^{-1}$, while keeping a constant PMMA-co-MAA 12 proportion of $0.1 \mathrm{mgmg}^{-1}$ PLA (Table 4). The suspensions of series 3 were analyzed both by DLS and TEM. For series 1 and 2, the mean diameter significantly decreased from $c$. 140 to $80 \mathrm{~nm}$ when $\mathrm{Cp}$ was decreased from 19.3 to $5.6 \mathrm{mgml}^{-1}$. The lower the polymer concentration in the organic phase, the lower the viscosity and the more rapid the diffusion into the aqueous phase, resulting in smaller nanodroplets in which PLA precipitates. However, both minimum and mean diameters went through a minimum in all series, increasing again at $C_{P}$ smaller than $2.8 \mathrm{mgml}^{-1}$ (e.g. mean diameter of $1.50 \mathrm{~nm}$ at $\mathrm{Cp}=0.6 \mathrm{mgml}^{-1}$ ). TEM observations confirmed that although particles prepared from a polymer solution of $\mathrm{Cp}=1.2$ $\mathrm{mgml}^{-1}$ were smaller $(38 \pm 12 \mathrm{~nm})$ than from a $\mathrm{CP}_{\mathrm{P}}=16 \mathrm{mgml}^{-1}$ solution $(97 \pm 33 \mathrm{~nm})$, the average diameter increased again $(55 \pm 17 \mathrm{~nm})$ for the lowest $\mathrm{Cp}=0.6 \mathrm{mgml}^{-1}$, In the latter case, the overall viscosity is probably so low that small nanoparticles are not prevented from coalescing as they are formed.

In short, the nanoparticle diameter was controlled by the viscosity of the organic phase and could be as small as $80 \mathrm{~nm}$, provided that the viscosity was low enough to allow rapid diffusion of the solvent into the aqueous phase, but high enough to avoid nanoparticle coalescence. 
Table 3. Influence of addition mode on the size distribution of PLA/PMMA-co-MA 12 (100:10) nanoparticles

Addition mode $\mathrm{C}_{\mathrm{P}}\left(\mathrm{mgml}^{-1} \mathrm{DMSO}\right)$

Mean diameter (nm) Minimum diameter

$(\mathrm{nm})$

$79 \pm 21$

$121 \pm 14$

$\begin{array}{ll}196 \pm 14 & 138 \pm 20 \\ 158 \pm 15 & 90 \pm 29\end{array}$

5.5

$61 \pm 5$

$172 \pm 9$

$36 \pm 12$

$115 \pm 29$

$101 \pm 5$

$69 \pm 12$

Table 4. Mean and minimum diameter of nanoparticles prepared from solutions of PLA/PMMA-co$M A_{12}$ (100:10) of different concentrations (CP) in DMSO, as measured by DLS and TEM

\begin{tabular}{|c|c|c|c|c|c|c|c|}
\hline $\mathrm{C}_{\mathrm{P}}$ & 1 & & 2 & & 3 & & \\
\hline DMSO & MeanD & MinD & MeanD & MinD & MeanD & MinD & Mean D \\
\hline $\mathrm{mgml}^{-1}$ & $(\mathrm{~nm})$ & $(\mathrm{nm})$ & $(\mathrm{nm})$ & $(\mathrm{nm})$ & $(\mathrm{nm})$ & $(\mathrm{nm})$ & $(\mathrm{nm})$ \\
\hline $19.3^{\mathrm{a}}$ & $142 \pm 10$ & $91 \pm 12$ & $135 \pm 18$ & $103 \pm 18$ & & & \\
\hline 17.6 & $126 \pm 13$ & $77 \pm 20$ & $127 \pm 11$ & $57 \pm 17$ & $135 \pm 11$ & $85 \pm 23$ & $97 \pm 33(\mathrm{n}=19)$ \\
\hline 11.0 & $102 \pm 2$ & $74 \pm 16$ & $10.3 \pm 19$ & $61 \pm 1.3$ & & & \\
\hline 5.6 & $81 \pm 5$ & $47 \pm 15$ & $85 \pm 7$ & $36 \pm 10$ & & & \\
\hline 28 & $79 \pm 5$ & $33 \pm 9$ & $103 \pm 2$ & $58 \pm 17$ & & & \\
\hline 1.2 & $92 \pm 9$ & $44 \pm 8$ & $120 \pm 13$ & $82 \pm 15$ & $93 \pm 41$ & $29 \pm 10$ & $38 \pm 12(\mathrm{n}=48)$ \\
\hline 0.6 & $151 \pm 9$ & $75 \pm 32$ & $115 \pm 14$ & $40 \pm 13$ & $113 \pm 15$ & $48 \pm 9$ & $55 \pm 17(n=23)$ \\
\hline
\end{tabular}

${ }^{a}$ Partial conversion into nanoparticles

Influence of the PLA molecular weight on the size distribution of PLA/PMMA-co-MA12 (100:10) nanoparticles.

Since the viscosity of the organic phase had a significant effect on the nanoparticle diameter, the effect of the molecular weight of PLA was also investigated. Nanoparticles were prepared from PLA of various origins: R-206 (Boehringer), Purasorb (Purac) and oligomers synthesized in the laboratory (Table .5). In a first set of experiments, the polymers were co-precipitated with PMMA-co-MA 12 from solutions of $\mathrm{CP}=17.6$ or $5.5 \mathrm{mgml}^{-1}$ of DMSO, In a second set of experiments, the three types of PLA were mixed together in order to increase the polymolecularity (PLA $\mathrm{M}_{1}$ and $M_{2}$ ). These two mixtures were co-precipitated with PMMA-co-MA12 from DMSO solutions of $\mathrm{CP}_{\mathrm{P}}=17.6 \mathrm{mgml}^{-1}$, using the addition modes $\mathrm{A}$ and $\mathrm{C}$.

For $\mathrm{Cp}=17.6 \mathrm{mgml}^{-1}$ in DMSO, the mean diameter decreased with $M_{n}$, in agreement with a decrease in the viscosity of the organic phase (Table 5). For example, R-206 formed nanoparticles with a diameter of $127 \pm 14 \mathrm{~nm}$, compared with $116 \pm 13 \mathrm{~nm}$ and $96 \pm 4 \mathrm{~nm}$ for Purasorb and oligomers, respectively. For $\mathrm{Cp}=5.5 \mathrm{mgml}^{-1}$, the mean diameter was independent of the type of PLA, while the minimum diameter was smaller for oligomeric PLA $(22 \pm 6 \mathrm{~nm})$, which is the lowest value of minimum diameter observed so far. However, such PLA oligomers should only be used to prepare nanoparticles for short-term applications, because hydrolytic degradation makes them soluble in aqueous media below a molecular weight of 0.7 to $1 \times 10^{3}[38,39]$.

In order to assess the effects of the polymolecularity of PLA on the size distribution, $M_{w} / M_{n}$ higher than 2.2 were obtained by mixing the three types of PLA (Table 5). $M_{n}$ was altered in parallel with $M_{w} / M_{n}$, which makes direct comparison difficult. 
Table 5. Mean and minimum diameter of PLA/PMMA-co-MA 12 (100:10) nanoparticles prepared from PLA of various origins (No. 1), and from mixtures of PLA (No. 2), using modes of addition A and C

\begin{tabular}{|c|c|c|c|c|c|c|c|}
\hline No PLA Source & $\begin{array}{l}\mathrm{M}_{\mathrm{n}} \\
\left(\mathrm{x} 10^{3}\right)\end{array}$ & $M_{w} / M_{n}$ & $\begin{array}{l}\mathrm{C}_{\mathrm{P}}\left(\mathrm{mg} \mathrm{ml}^{-}\right. \\
\left.{ }^{1} \mathrm{DMSO}\right)\end{array}$ & Addition & $\begin{array}{l}\text { MeanD } \\
(\mathrm{nm})\end{array}$ & $\begin{array}{l}\text { MinD } \\
(\mathrm{nm})\end{array}$ & $\begin{array}{l}\text { Max D-min } \\
\text { D (nm) }\end{array}$ \\
\hline $\mathrm{R}-206$ & 47.75 & 1.77 & 17,6 & A & $127 \pm 14$ & $77 \pm 21$ & \\
\hline Purasorb & 14.25 & 1.82 & 17,6 & & $116 \pm 13$ & $74 \pm 18$ & \\
\hline Oligomers & 4,00 & 200 & 17,6 & & $96 \pm 4$ & $64 \pm 14$ & \\
\hline R-206 & 47.75 & 1.77 & 5,5 & A & $85 \pm 6$ & $59 \pm 14$ & \\
\hline Purasorb & 14.25 & 1.82 & 5.5 & & $91 \pm 10$ & $60 \pm 22$ & \\
\hline Oligomers & 4.00 & 2.00 & 5.5 & & $91 \pm 19$ & $22 \pm 6$ & \\
\hline $\begin{array}{ll}2 & \text { R-206 }\end{array}$ & 47.75 & 1.77 & 17.6 & $\mathrm{~A}$ & $126 \pm 6$ & $66 \pm 24$ & $157 \pm 98$ \\
\hline $\mathrm{M}_{1}$ & 28.00 & 2.24 & 17.6 & & $119 \pm 7$ & $66 \pm 13$ & $128 \pm 44$ \\
\hline $\mathrm{M}_{2}$ & 20.00 & 2.43 & 17.6 & & $120 \pm 10$ & $84 \pm 6$ & $89 \pm 30$ \\
\hline Purasorb & 14.25 & 1,82 & 17.6 & & $116 \pm 13$ & $74 \pm 18$ & $106 \pm 81$ \\
\hline Oligomers & 4.00 & 2.00 & 17,6 & & $96 \pm 4$ & $64 \pm 14$ & $91 \pm 39$ \\
\hline R-206 & 47.50 & 1,77 & 17,6 & $\mathrm{C}$ & $137 \pm 5$ & $90 \pm 20$ & $127 \pm 82$ \\
\hline $\mathrm{M}_{1}$ & 28.00 & 2,24 & 17,6 & & $134 \pm 4$ & $86 \pm 30$ & $138 \pm 92$ \\
\hline $\mathrm{M}_{2}$ & 20.00 & 2,43 & 17,6 & & $133 \pm 18$ & $54 \pm 7$ & $183 \pm 53$ \\
\hline
\end{tabular}

The data obtained for all suspensions prepared according to addition mode $\mathrm{A}$ for $\mathrm{Cp}=17.6 \mathrm{mgml}^{-1}$ are gathered in one single graph (diameter vs $\mathrm{M}_{\mathrm{n}}$ ) (Fig. 1). It can be seen that down to $\mathrm{M}_{\mathrm{n}}=14,2 \times 10^{3}$, the mean diameter decreased very slowly with decreasing $M_{n}$, independently of $M_{W} / M_{n}$, while the minimum diameter remained unchanged (between 64 and $84 \mathrm{~nm}$ ). However, the difference between the extreme values of the diameter distribution, as found for R-206 (157 nm), $M_{1}(128 \mathrm{~nm})$ and $M_{2}(89$ $\mathrm{nm}$ ), suggests a possible influence of $M_{w} / M_{n}$ on the polydispersity of the nanoparticle distribution (Table 5). The larger $M_{w} / M_{n}$, the narrower the nanoparticle size distribution. An explanation could be that shorter chains of polydisperse samples also act as surfactants and contribute to better prevent the nanoparticles from coalescing, With addition mode $\mathrm{C}$, the reverse effect on size distribution was observed, and larger nanoparticles with a mean diameter of ca, $135 \mathrm{~nm}$ were formed independently of $\mathrm{M}_{\mathrm{n}}$ and $M_{w} / M_{n}$.

\section{How to concentrate nanoparticle suspensions?}

Suspensions of nanoparticles containing PMMA-co-MA $\mathrm{A}_{\mathrm{x}}$ copolymers are typically unstable at acidic $\mathrm{pH}$ below $\mathrm{pH}$ 4.5. Indeed, sodium carboxylate groups of MA units are converted into uncharged carboxylic acid groups, which are no longer able to stabilize the nanoparticles. They can be readily suspended again in the same volume of phosphate buffer with unaltered size distribution. The 'resuspension' of acidified nanoparticles in smaller aqueous volumes was investigated here, with the purpose of concentrating the suspensions. With concentrated suspensions, one can reduce the administration volume and the drug loading for equivalent doses, One can also limit drag release during storage. A $0.8 \mathrm{mgml}^{-1}$ suspension of PLA/PMMA-co-MA 12 (100:10) nanoparticles was acidified at $\mathrm{pH} 4$ with acetic acid, and the nanoparticles were sedimented by centrifugation at 3500 ipm. 


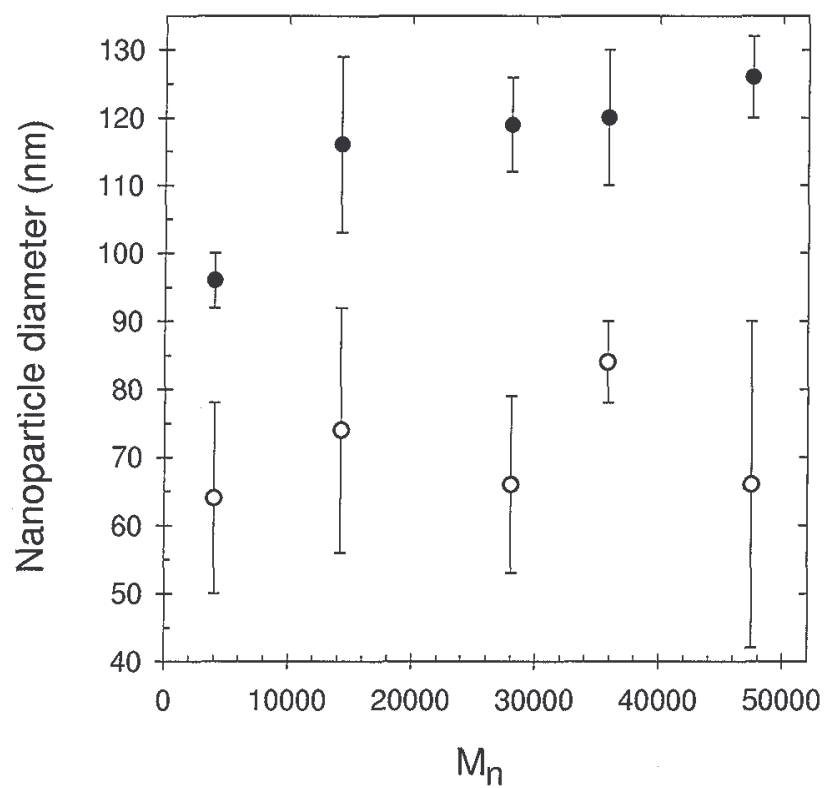

Figure 1. Influence of the number average molecular weight $\left(M_{n}\right)$ of PLA on mean diameter $(\bullet)$ and minimum diameter $(O)$ of PLA/PMMA-co-MA 12 (100:10) nanoparticles; $C p=17.6 \mathrm{mgml}^{-1}$ in DMSO

The substitution of the acidic supernatant by phosphate buffet $(0.13 \mathrm{M}, \mathrm{pH} 7.4)$ allowed the nanoparticles to be entirely resuspended up to a concentration of $8 \mathrm{mgml}^{-1}$ (CPLA) (Table 2). Size distribution of concentrated suspensions was unaltered after 5 day storage at $4^{\circ} \mathrm{C}(136 \pm 12 \mathrm{~nm})$, except for a faint precipitation. Above a nanoparticle concentration of $8 \mathrm{mg} \mathrm{ml}^{-1}$, the suspension was very turbid, and larger mean diameter and broader polydispersity were found. Finally, resuspension in phosphate buffer was poor when the nanoparticles were dried just after separation from the acidic supernatant, either under vacuum or by lyophilization. Lyoprotecting additives can be used to preserve the size distribution of nanoparticles once lyophilized [29].

Degradability and stability ofPLA/PMMA-co-MA 12 (100: 10) nanoparticles Nanoparticles stored in non-buffered suspensions at $37^{\circ} \mathrm{C}$.

Long-term degradation kinetics of polylactide nanoparticles have been previously reported in the literature to determine how long suspensions can be stored [40, 41]. For instance, unpurified PLA nanoparticles $\left(\mathrm{M}_{\mathrm{W}} \equiv 90000\right)$ prepared by solvent displacement with Poloxamer showed no significant change in molecular weight and particle size distribution when stored at $4^{\circ} \mathrm{C}$ or at room temperature in buffered medium for one year [40], In non-buffered conditions, PLA molecular weight $\left(\mathrm{M}_{\mathrm{W}}\right)$ decreased as the result of the accumulation of carboxylic acid end groups formed by the hydrolytic scission of the polyester chains. At $37^{\circ} \mathrm{C}, \mathrm{M}_{\mathrm{W}}$ had decreased $22 \%$ after 1 month and $62 \%$ after 2 months. 

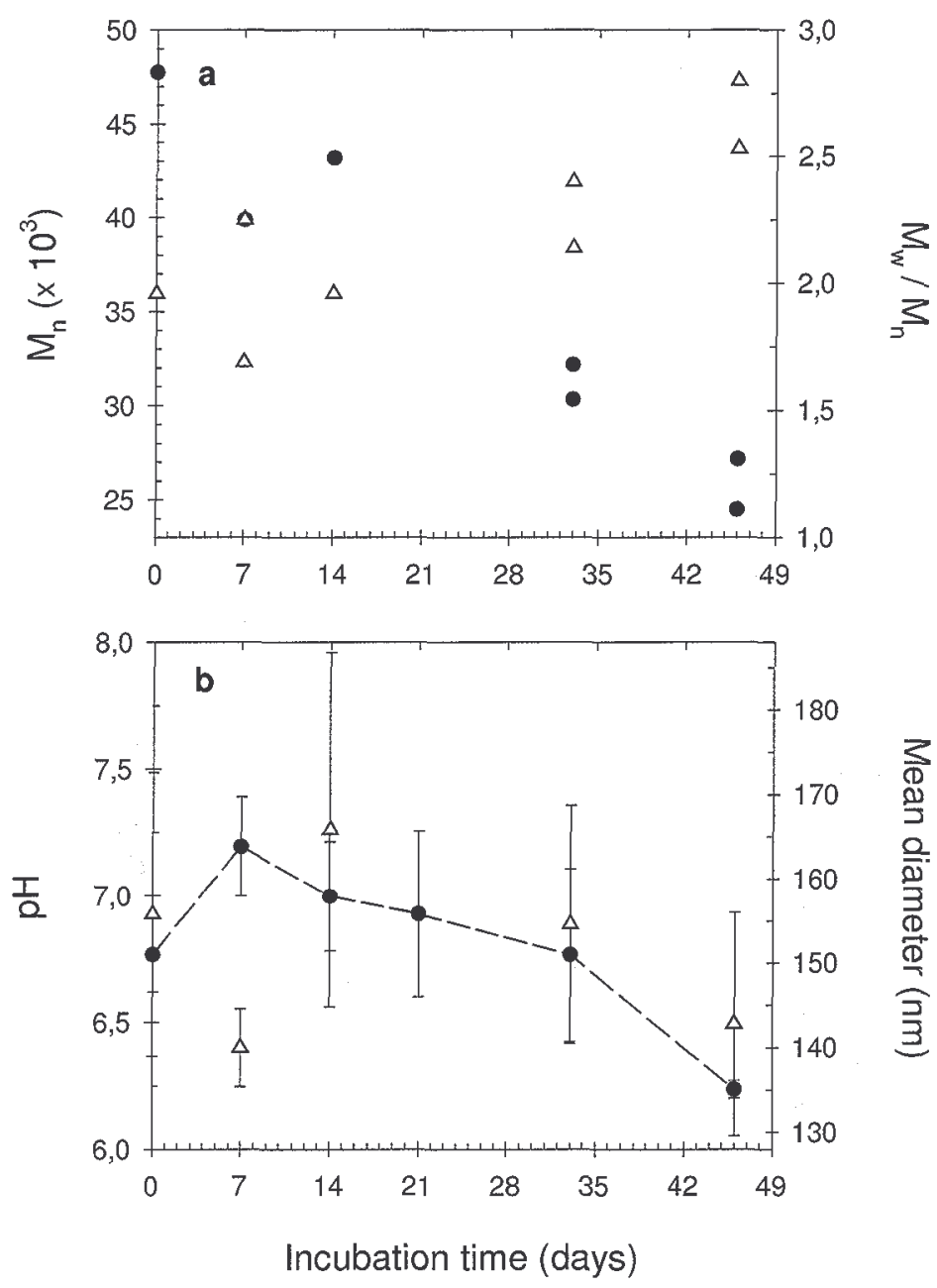

Figure 2. (a) $M_{n}(\bullet)$ and $M_{w} / M_{n}(\Delta)$ of PLA in non-buffered aqueous suspension; (b) pH of incubation medium $(\bullet)$ and mean nanoparticle diameter $(\Delta)$ vs time of incubation fbt suspensions stored at $37^{\circ} \mathrm{C}$; $C P L A=2 \mathrm{mgml}^{-1}$

In this work, the short-term stability of the PLA nanoparticles was studied at $37^{\circ} \mathrm{C}$ in non-buffered conditions, by measuring $\mathrm{M}_{\mathrm{n}}, M_{w} / M_{n}, \mathrm{pH}$, and particle size (Fig. 2). In a second study, the issue of longer-term stability at $4^{\circ} \mathrm{C}$ in buffered conditions was addressed, based on time dependence of the suspension turbidity (Fig. 3).

In non-buffered media, the $\mathrm{M}_{\mathrm{n}}$ of PLA was found to decrease slowly from 47.7 .5 to ca. $27.0 \times 10^{3}$ in 46 days (Fig. 2a). The loss of $\mathrm{M}_{n}$ was $9 \%$ after 7 days, $27 \%$ after 28 days, and ca. $45 \%$ after 46 days. This degradation profile is very much comparable with that reported by Lemoine et al. in the case of PLA/Poloxamer nanoparticles (i.e. $\mathrm{M}_{\mathrm{W}}$ loss of $22 \%$ after 28 days) [40]. The polymolecularity of PLA increased in parallel from 1.9 to 2.7 at day 46, as the result of the formation of oligomers.

The $\mathrm{pH}$ of the suspension decreased slowly until 33 days, and more significantly afterwards, down to 6.2 after 46 days (Fig. 2b). This observation indicates that oligomeric chains terminated by carboxylic acid reached the critical $\mathrm{M}_{\mathrm{n}}$ below which they are soluble in the aqueous phase. Finally, the loss in $M_{n}$ has no effect on the mean nanoparticle diameter, which remained basically in the 140 to $165 \mathrm{~nm}$ range (Fig. 2b). The same observation holds for the particle size distribution, except at day 14 where it was unexplainably broad. In summary, the size distribution of PLA/PMMA-co-MA nanoparticles was unaltered when stored at $37{ }^{\circ} \mathrm{C}$ in pure water, although $M_{n}$ of the PLA chains decreased by a factor of 2 in 46 days. 

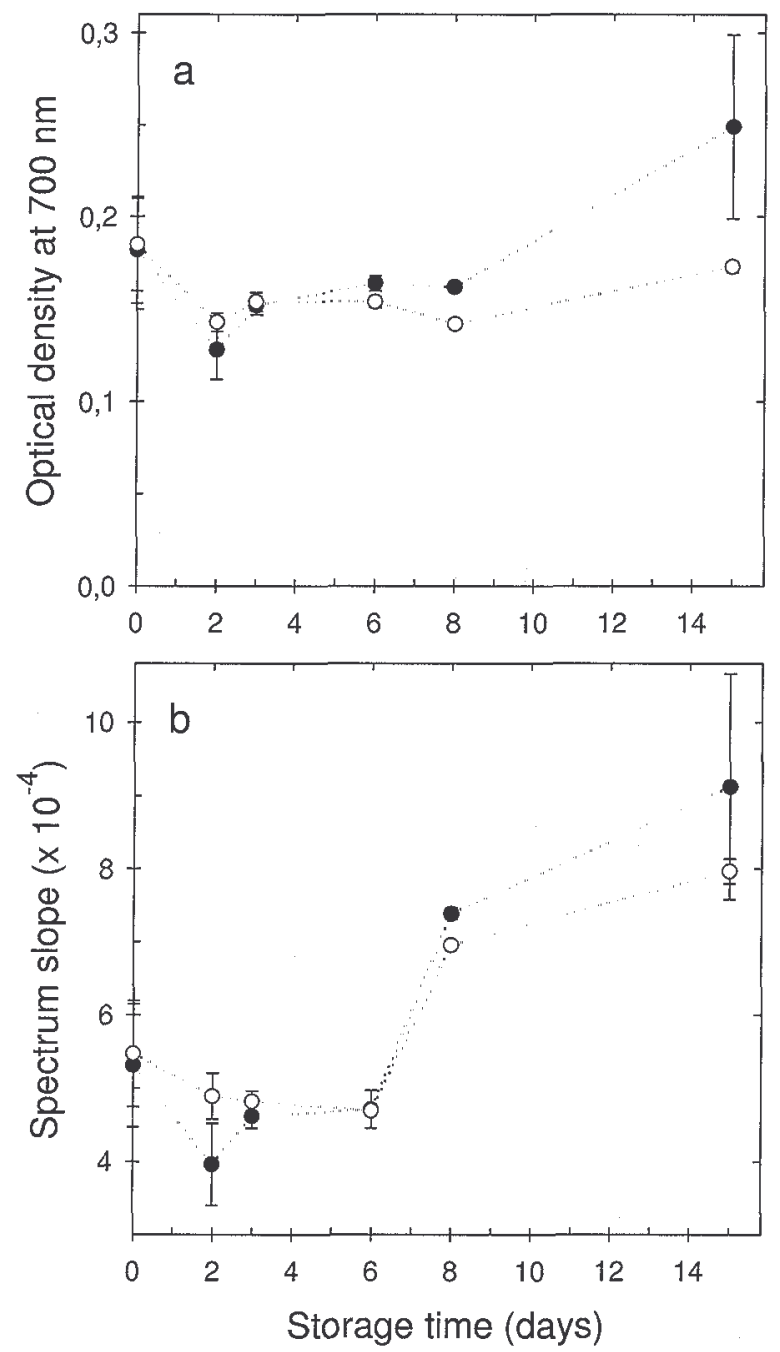

Figure 3. (a) Optical density at $700 \mathrm{~nm}$ and (b) slope of the UV-visible spectrum between 700 and 850 $n m$ vs time of storage at $\mathrm{pH} 6(\bullet)$ and $\mathrm{pH} 7.4(\mathrm{O})$ for buffered suspensions stored at $4^{\circ} \mathrm{C} ; \mathrm{C}_{P L A}=$ $2 m g m l^{-1}$.

Nanopariicles stored in buffered conditions at $4^{\circ} \mathrm{C}$.

The stability of biodegradable nanoparticles in suspension is usually assessed by the time dependence of the particle size distribution measured by DLS or TEM, $\mathrm{pH}$, drug encapsulation, and in case of longterm studies polymer molecular weight distribution $[13,30,34]$, What we already found is that although $M_{n}$ and $M_{w} / M_{n}$ of PLA change with time, the particle size distribution is essentially unaltered over a period of 46 days (at $37^{\circ} \mathrm{C}$ in non-buffered conditions). The main visible modification is the formation of sediments after a while, but larger particles in suspension are never detected by DLS. It thus appears that if aggregates of nanopartides are formed, they cannot be maintained in suspension, but readily precipitate.

For this reason, the extent of this precipitation should also be measured as a criterion of instability, for instance to be able to compare the efficiency of various stabilizing copolymers, or to determine how much material has remained in suspension prior to use, Measurement of turbidity is a valuable tool to trace the formation of larger particles in suspension (increase of turbidity) and characterize the sedimentation of large aggregates either with time or upon addition of electrolytes (decrease of turbidity) [30], Here, the turbidity was characterized by the optical density at $700 \mathrm{~nm}$. The turbidity of two PLA/PMMA-co-MAi2 suspensions stored at $4^{\circ} \mathrm{C}$ and buffered at $\mathrm{pH} 6$ and 7,4 was measured, after slight centrifugation at $3500 \mathrm{rpm}$ in order to sedimentate large aggregates (Fig, 3a). The slope of the UV-visible spectrum between 600 and $850 \mathrm{~nm}$ was also calculated from the optical density at 600,700 and $850 \mathrm{~nm}$ (Fig, 3b). At both $\mathrm{pH}$, optical density (OD) and slope of the spectrum started to decrease 
after 2 days. They leveled off afterwards, until day 6 for OD and day 8 for the spectrum slope. They both finally increased more markedly at $\mathrm{pH}$. The initial decrease of the two parameters indicates a slight decrease in turbidity, due to the removal of larger particles which did not remain in suspension. However, the turbidity stopped diminishing after 2 days, and was even observed to increase later on. Two reasons could account for this observation. Either the particles increased in size, but not enough to sedimentate, or there were polymer chains in solution which could absorb in UV, such as PLA oligomers formed by hydrolysis. This second phenomenon is consistent with the higher OD over the whole UV-visible spectrum after 8 days and the higher spectrum slope after 6 days. The two phenomena could occur simultaneously, but no drastic change in particle diameter was found over this period of time (not shown), Even though turbidity is a good criterion for stability, it should preferably be used for comparison purposes over short periods of time before oligomers are formed. Suspensions of PLA/PMMA-co-MA12 (100:10) nanoparticles appear to be stable until 6 days when stored at pH 7 4, with no major nanoparticle aggregation, as confirmed by turbidimetry.

\section{Labeling of PLA nanoparticles with biotin}

The carboxylic acid groups of PMMA-co-MA copolymers can be advantageously used to covalently attach markers, via either ester or amide bonds. Biotin-cadaverin was selected as the marker, since biotin is known for being selectively recognized by avidin or streptavidin proteins, which in turn can be either labeled with fluorescent molecules suited to the observation by fluorescence microscopy, or coupled to gold nanoparticles detectable by TEM [56]. Conjugates of PMMA-co-MA25 and biotincadaverine were prepared by reaction of biotin-cadaverin with the carboxylic acid groups of the copolymer after activation with dicyclohexylcarbodiimide and N-hydroxysuccinimide (Scheme 1), The theoretical biotin content was $10 \mathrm{~mol} \%$ of the MA units, or $2.5 \mathrm{~mol} \%$ of the copolymer. The PMMAco-MA25-biotin conjugate was successfully co-precipitated with PLA into stable nanoparticles, with a mean diameter of $1.56 \pm 12 \mathrm{~nm}$. Biotinylated nanoparticles were detected by fluorescence microscopy after revealing with a NeutrAvidin-rhodamine conjugate, confirming that biotin molecules linked to PMMA-co-MA were available at the nanoparticle surface, at least partially, and were recognized by avidin. Biotiny-lated nanoparticles $(11 \mathrm{mg})$ were injected into the rat small intestine that had been ligatured. On sections prepared for fluorescence microscopy and revealed by NeutrAvidin-rhodamine, red fluorescent grains typical of biotinylated nanoparti-cles were seen in Peyer's patches of the ileum, and in peripheral organs (liver, bladder, kidneys) as soon as $10 \mathrm{~min}$ after infiltration. The density of nanoparticles was low and the fluorescence was not as intense as that of commercially available biotinylated polystyrene nanoparticles (e.g. FluoroSpheres-biotin, 1- $\mu \mathrm{m}$ diameter). The surface density in biotin was probably not high enough, either because the degree of substitution of PMMA-co-MA with biotin was too low, or because part of the biotin molecules tended to migrate into the core of the particles, thus preventing them from being recognized by avidin.

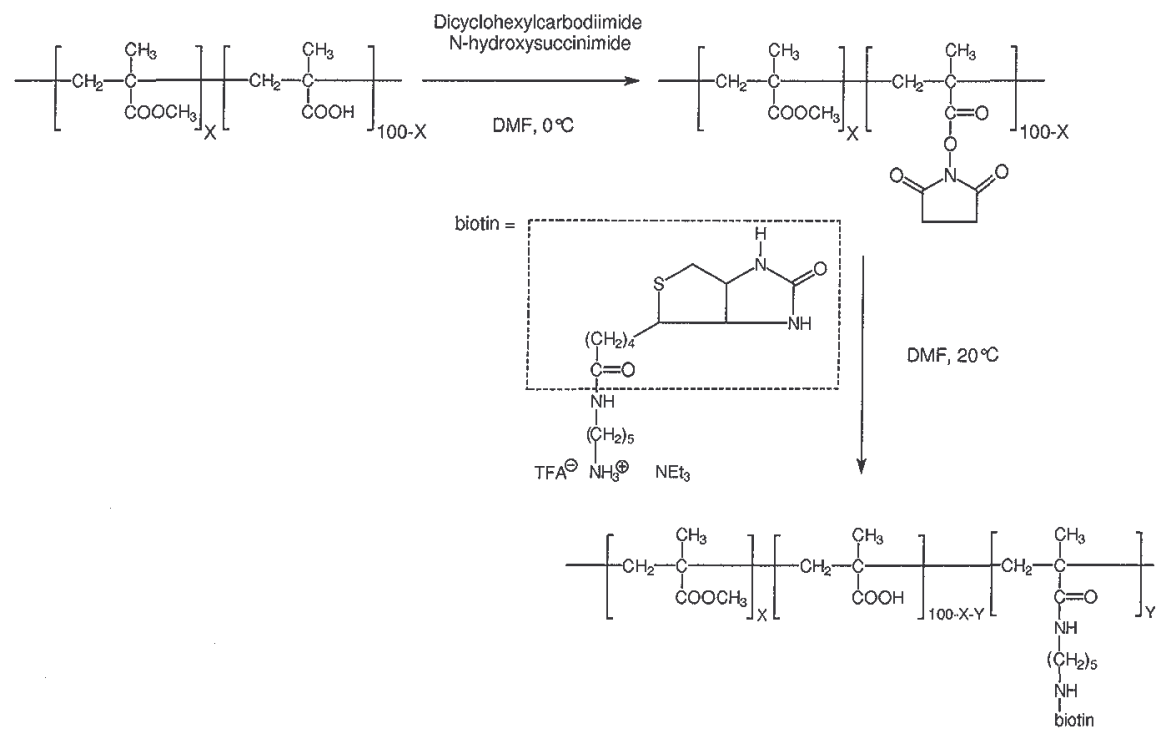

Scheme 1. Synthesis of PMMA-co-MA 25 -biotin conjugate. 
On sections prepared for TEM and revealed by streptavidin coupled to gold nanoparticles (10-nm diameter), biotinylated nanoparticles could also be detected as black grains corresponding to the gold particles. For example, such black grains were seen in epithelial cells at the border of the Peyer's patches, in the cytoplasm and in the intercellular space of lymphocytes of the Peyer's patches lymphoid follicules (Fig. 4) and in the liver and bladder. However, on control sections from rats that had not received biotinylated nanoparticles, a significant number of gold nanoparticles were also found, often on dense structures of the cytoplasm appearing like mitochondrias, for instance at the villosities and Peyer's patches and in the kidneys. This suggests that there might be an interference with endogeneous biotin in these tissues, However, the presence of PLA nanoparticles in the intestinal epithelial layer and in peripheral organs at very early times after infiltration was consistently confirmed via other labeling and immunostaining techniques.

Covalent coupling of markers like biotin onto PMMA-co-MA, located at the surface of PLA nanoparticle, is a valuable strategy that allows detection by fluorescence and electronic microscopy in tissues, provided that the selected markers are not endogenously present. With such a strategy, the risk of the marker being released from the nanoparticles is low.

Release can occur if part of the marker is non covalently associated with the copolymer or if the copolymer-marker bond is hydrolyzed. In the case of biotin, eventual free biotin is probably eliminated during the preparation of biotinylated nanoparticles, since it includes two dialysis steps in aqueous phase and one precipitation step with organic solvents. A cleavage of the amide bond between biotin and the copolymer (or the amide bond of the biotin-cadaverin molecule) is not likely to occur in the short-term. Finally, there is the risk of having the stabilizing copolymer released from the PLA matrix, but this risk is inherent to any nanoparticulate carrier made of labeled linear polymer chains, as opposed to cross-linked nanoparticles.

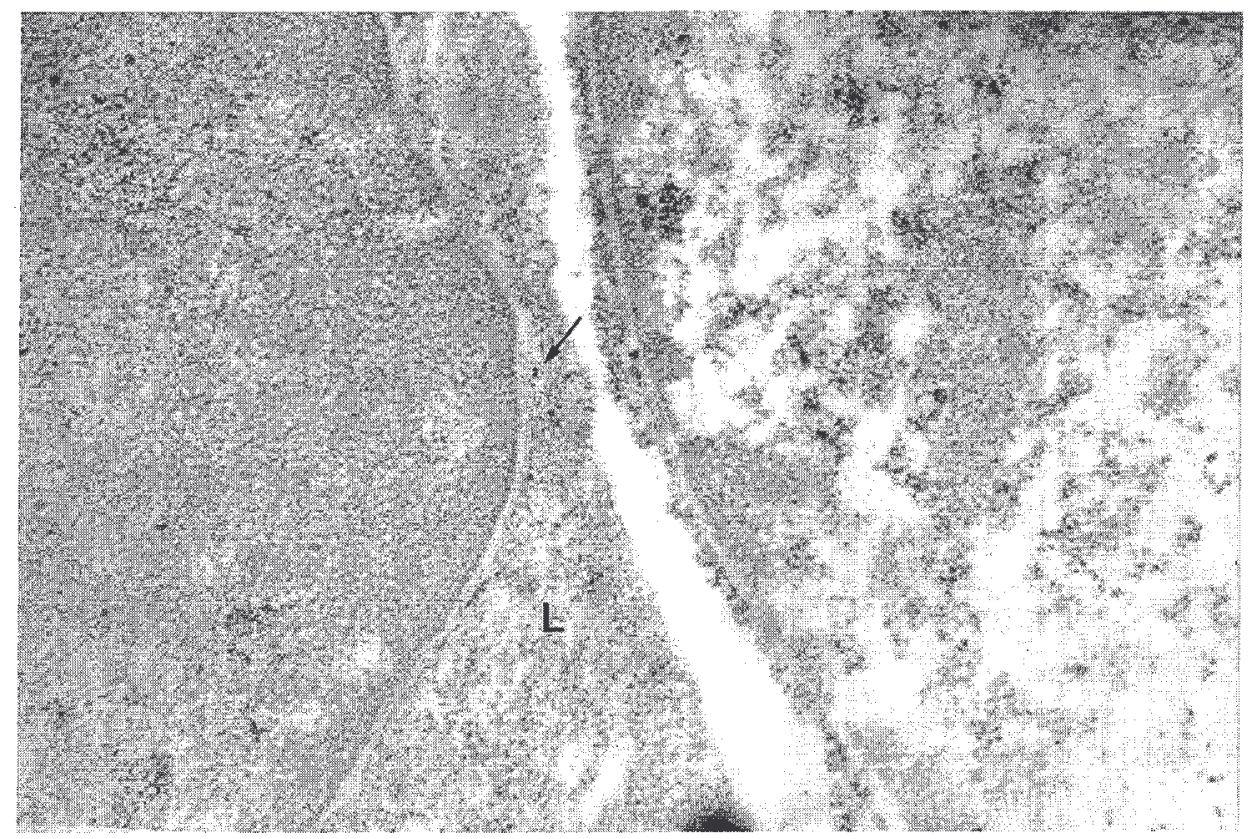

Figure 4. TEM observations after infiltration of biotinylated nanoparticles in the anterior intestine. Nanoparticles were revealed with streptavidin-gold nanoparticles $(10 \mathrm{~nm})$ Here, gold nanoparticles are detected in the cytoplasm of a lymphocyte $(L)$ in a lymphoid follicule of a Peyer's patch, $10 \mathrm{~min}$ after infiltration (x 20000$)$

\section{Conclusion}

This work demonstrates that nanoparticules can be easily prepared from poly(D,L-lactide) coprecipitated with tailored amphiphilic PMMA-co-MA copolymers, following a one-step procedure from DMSO with no need for additional stabilizing agents. This straightforward technique has several advantages over the classical nanoprecipitation. Only small proportions of PMMA-co-MA are usually required to provide sufficient stabilization against coalescence (around $10 \mathrm{wt} \%$ of the PLA matrix), There is no need for purification of the nanoparticles, as the copolymer remains entangled with PLA at the nanoparticle surface, The nanoparticle diameter is dependant on the polymer concentration in the organic phase and mean diameters as low as $60 \mathrm{~nm}$ can be obtained. The most interesting feature of our 
system is the presence of PMMA-co-MA carboxylic groups, which provides a means to modify the surface of the nanoparticles. As an example, PMMA-co-MA was labeled with biotin, and nanoparticles were successfully traced via the biotin-avidin interaction on histologic sections by fluorescence microscopy and TEM.

Other copolymers, such as methacrylic copolymers bearing sulfonate groups [57] as well as PLA-bPEO block copolymers, are also able to stabilize PLA nanopar-ticles. Hydrophilic moieties like sulfonate groups and PEO chains have the advantage of being insensitive to a decrease of $\mathrm{pH}$, which maintains the stability of the nanoparticles, even in acidic environments, e.g. in gastric fluids. Future directions will focus on the design of amphiphilic biodegradable copolymers [58], copolymers with brush-like architectures and functional copolymers bound with species known to be recognized by specific receptors $[59,60]$.

\section{Acknowledgements}

Financial support from the 'Region Wallonne' and the 'Services Federaux des Affaires Scientifiques, Techniques et Culturelles' in the framework of the 'PAI 4-11: Chimie et catalyse supramoleculaire' are gratefully acknowledged. The authors are indebted to P. Ernould, 0. Halleux, $\theta$, Detaille, M, Degeneffe, and J. Piret for technical assistance.

\section{References}

[1]. M.. J. Alonso, Drugs Pharm Sci. 77, 203 (1996),

[2]. D Quintanai-Gueirero, E. Alleman, H. Fessi and E Doelker, Drug Devel. Ind. Pharm. 24, 1113 (1998).

[3]. M. Julienne, M Alonso, J. Gomez and J.-P. Benoit, Drug Devel Ind. Pharm.. 18, 1063 (1992).

[4]. T. Verechia, P. Huve, M. Veillard, G Spenlehauei and P. Couvieui, J Biomed. Mater. Res 27, 1019 (1993).

[5] P. Quellec, R Gief', L Peirin, E Dellacheiie, F. Sommer, J.-M. Verbavatz and M. J. Alonso, J. Biomed. Mater. Res 42 , 45 (1998).

[6]. M. Ueda, A. Iwara and J Kieuter,,. Microencapsulation 15, 361 (1998).

[7]. D. Quintanar-Gueлeio, H. Fessi, E. Alleman and E. Doelker, Int.. J. Pharm.. 143, 1.33 (1996)..

[8] D Quintanai-Guerrero, E Alleman, E Doelker and H Fessi, Colloid Polym.. Sci 275, 640

(1997).

[9]. D Quintanai-Gueirero, E Alleman, H Fessi and E, Doelker, Int. I. Pharm. 188, 155 (1999)

[10]. J. Molpeceres, M. Guzman, M. R. Abeituras, M. Chacon and L, Beiges,.J. Pharm.. Sci. 85, 206 (1996).

[11]. J. Kristl, E. Alleman and R. Gurny, Acta Pharm.. 46, 1 (1996).

[12]. S. E. Dunn, A. G, A. Coombes, M. C. Gainett, S. S. Davis, M. C. Davies and L Ilium, / Control Rel. 44, 65 (1997)

[13]. J. Rodiigues, H. Fessi, C. Bories, F. Puisieux and J -P. Devissaguet, Int. I. Pharm. 126, 253 (1995).

[14].. T. Jung, A. Breitenbach and T. Kissel, J. Control. Rel. 67, 157 (2000)

[15], H. Fessi, F, Puisieux, J.-P. Devissaguet, N Ammoury andS. Benita,Int. j. Pharm 55, R1 (1989),

[16]. J..-C. Leioux, F De Jaeghere, B,, Annex, E Doelker and R,, Gumy, Life Sci. 57, 695 (1995).

[17] D Quintanar-Guenero, A. Ganem-Quintanai, E Alleman, H Fessi and E Doelker, J Microencapsulation 15, 107 (1998)

[18]. C, Grandfils, N, Nihant, R, Jerome and P, Teyssie, US Patent No. 5,962,566 (1999).

[19] A, T, Florence, Pharm.. Res 14, 259 (1997),

[20], Registry of Toxic Effects of Chemical Substances, National Institute for Occupational Safety and Health, Miciomedex (1991).

[21]. G,, Moineau, M, Minet, P, Dubois, P, Teyssie, T Senninger and R Jerome, Macromolecules 32, 27 (1999).

[22]. G, Moineau, M, Minet, P, Dubois, P, Teyssie and R,, Jerome, Macromolecules 32, 8277 (1999),

[23]. C, Scala, G, Cenacchi, C, Ferrari, G Pasquinelli, P, Preda and G, Manaia, J Histochem.. Cytochem.. 40, 1799 (1992).

[24]. A,-M, Le Ray, M, Vert, J.-C. Gautier and J .-P.. Benoit, Int J Pharm.. 106, 201 (1994)

[25]. M..-C. Venier-Julienne and ,J,,-P., Benoit, Pharm. Acta Helv. 71, 121 (1996).

[26] M, Berton, E, Alleman, C, A. Stein and R,, Gumy, Eur. I. Pharm.. Sci. 9, 163 (1999).

[27]. C, Rouzes, R, Gief, A De Souza Delgado and E,, Dellacheiie,,/ Biomed. Mater. Res 50, 557 (2000).

[28]. P, D, Scholes, A. G, A Coombes, L, Ilium, S S, Davis, J. F, Watts, C, Ustariz, M, Vert and M, C, Davies, J, Control. Rel $59,261(1999)$

[29] E De Jaeghere, E, Alleman, J.-C, Leioux, W. Stevels, I. Feijens, E,, Doelker and R Gurny, Pharm, Res 16, 859 (1999).

[30]. S, Stolnik, S. Dunn, M, Gainett, M. Davies, A, Coombes, D, Taylor, M, Irving, S, Purkiss, T. Tadros, S Davis and L Ilium, Pharm Res 11, 1800 (1994).

[31]. R, Gref, Y, Minamitake, M, T, Peiacchia, V Trubetskoy, V. Torchilin and R, Langei, Science 263,1600(1994)

[32]. D Bazile, C, Piud'homme, M, T Bassoullet, M, Marlard, G. Spenlehauer and M, Veillard, J. Pharm.. Sci. 84, 493 (1995)

[33]. Z Lu, J. Bei and S, Wang, J. Control Rel 61, 107 (1999).

[34]. S. Guterres, H. Fessi, G, Barrat, J.-P Devissaguet and F Puisieux, Int. J Pharm. 113, 57 (1995) [35].. A. Maiuyama, T.

Ishihaia, J.-S Kim, S W. Kim and T. Akaike, Bioconj Chem. 8, 735 (1997),,

[36].. T. Govender, S. Stolnik, M, C Garnett, L. Ilium and S. S Davis, J Control Rel 57, 171 (1999).

[37]. C. Thomasin, H P. Meikle and B Gander, J. Pharm Sci. 87, 269 (1998)..

[38]. I. Giizzi, H, Garreau, S.-M. Li and M. Vert, Biomaterials 16, 305 (1995)

[39]. C. Braud, R Devarieux, A. Atlan, C. Ducos and M. Vert, J. Chromatogr. B Biomed. Sci. Appl. 27,73(1998).

[40].. D Lemoine, C Francois, F. Kedzierewicz, V. Preat, M Hoffman and P. Maincent, Biomaterials 17, 2191 (1996)

[41]. M. D. Coffin and J. W. McGinity, Pharm. Res 9, 200 (1992).

[42]. P. Jani, G. W. Halbert, J. langridge and A. T. Florence,.J. Pharm. Pharmacol 42, 821 (1990) 
[43]. P. Calvo, M. J.. Alonso, J. L. Vila-Jato and I R, Robinson, J Pharm. Pharmacol 48,1147 (1996).

[44]. P. Calvo, C Thomas, M. J. Alonso, J. L. Vila-Jato and J. R. Robinson, Int. I. Pharm. 103, 283 (1994).

[45] V Labhastwai, C. Song, W. Humpfrey, R Shebuski and R. J. Levy, J. Pharm. Sci. 87, 1229 (1998)

[46] C. Song, V. Labhasetwar, X. Cui, T. Underwood and R. J, Levy, J Control. Rel 54, 201 (1998).

[47] J.-C. Leroux, P Gravel, L Balant, B. Volet, B M Annei, E Alleman, E Doelker and R Gurny, J. Biomed. Mater. Res 28, 471 (1994).

[48] E Alleman, P Gravel, J.-C Leroux, L Balant and R Gurny, J Biomed Mater. Res 37, 229 (1997).

[49] M. P Desai, V Labhasetwar, E Walter, R J Levy and G. L Amidon, Pharm. Res. 14, 1568 (1997)

[50]. S McClean, E Piossei, E. Meehan, D O'Malley, N Clarke, Z Ramtoola and D Brayden, Eur. J. Pharm. Sci. 6, 153 (1998)

[51]. D, V, Bazile, C, Ropert, P. Huve, T. Verrechia, M. Marlard, A. Frydman, M. Veillard and G. Spenlehauer, Biomaterials 13, $1093(1992)$

[52] C. Passirani, G. Barratt, J.-P. Devissaguet and D Labarre, Pharm. Res 15 (1998).

[53]. I. Dos Santos, J.-L. Morgat and M. Vert, Polymer Int. 48, 283 (1999).

[54]. S. Ponsart, J. Coudane, J. Morgat and M. Vert,J. Labelled Compounds Radiopharmaceut 43, 271 (2000).

[55]. S Ponsart, J. Coudane and M. Vert, Biomacromolecules 1, 275 (2000)

[56] R P. Haugland, Handbook of Fluorescent Probes and Research Chemicals, Molecular Probes

(1996)

[57]. S. Gautier and R Jerome, in: Proceedings 27th Int. Symp. Controlled Release Bioactive Materials, Paris, \# 8130 (2000).

[58] C Detrembleur, M Mazza, X Lou, O Halleux, P Lecomte, D Mecerreyes, J L Hedrick and R. Jérôme, Macromolecules 33, 7751 (2000)

[59]. C.-M. Lehr,,J. Control. Rel 65, 19 (2000).

[60]. G Russell-Jones, L. Arthur and H. Walker, Int J Pharm. 179, 247 (1999) 